\title{
Status Disclosure in HIV Infected Children in Abakaliki, Ebonyi State, Southeast, Nigeria
}

\author{
Orji $\mathrm{ML}^{1}$, Onyire $\mathrm{NB}^{2}$, Onwe $\mathrm{OE}^{3}$
}

\begin{abstract}
Introduction: The emotional and psychosocial issues surrounding HIV infection make status disclosure herculean task. Many caregivers are unwilling to disclose because they are afraid of possible unpleasant outcome. The objective of this study were to determine the prevalence rate of HIV status disclosure and possible effect on ART adherence. Material and Methods: It was a cross sectional study that involved consecutive recruitment of 94 confirmed HIV infected children aged 5-17 years. Structured questionnaire was used to obtain information on socio-demographic, disclosure and adherence. Assessment of adherence was done in the clinic by direct questioning and pill count. Results: A total of 31 (33.0\%) have received a form of information regarding their HIV status. The mean age of disclosure was $12.48 \pm 2.46$ years. Majority $(95.5 \%)$ of the children that received full information about their HIV status were adolescents. Circumstantial disclosure was seen in 25 (80.6\%) out of the 31 subjects. A total of $61.3 \%$ of HIV status disclosure was done in hospital setting by health workers and $81.8 \%$ of subjects that were given full information about HIV were from health workers in a hospital setting. There was however no relationship between adherence to ART and status disclosure $(p=0.832)$. Conclusion: Age of status disclosure was rather late in this study and majority of the disclosure were consequent to prevailing circumstances in the subjects' life. A step-wise approach to disclosure that entailed giving age dependent information as from the age of seven years is therefore recommended
\end{abstract}

Key words: Adherence, ART, HIV infection, Status disclosure

\section{Introduction}

Informing the child about his/her HIV status is a delicate task that is clouded with emotional and controversial issues, which is to be carried out by caregiver and/or health care provider $^{1}$. Although there is no consensus to when HIV disclosure should be made to children, issues to be considered may include the needs, beliefs and feelings of both the child and the caregiver ${ }^{1,2}$. Considerations for the child's ability to comprehend the information and cope with the knowledge that they are HIV infected and caregiver's ability to cope with the stress of disclosure. Severely depressed or anxious caregivers may need to
${ }^{1}$ Dr. Maria-Lauretta Orji, MBBS, FWACP Consultant Paediatrician, ${ }^{2} \mathrm{Dr}$. Nnamdi Benson, Onyire MBBS, FWACP, Associate Professor, ${ }^{3} \mathrm{Dr}$. Emeka Onwe Ogah, MBBS, FWACP, Consultant Paediatrician. All from the Department of Paediatrics, Federal Teaching Hospital Abakaliki, Ebonyi State, Nigeria.

\author{
Address for correspondence \\ Maria Lauretta Orji \\ Department of Paediatrics, \\ Federal Teaching Hospital Abakaliki (FETHA), \\ Ebonyi State, Nigeria. \\ Tel No; +2347034565992 \\ E-mail: drlauretta2002@gmail.com
}

\author{
Acknowledgements: None \\ Funding: Nil \\ Conflict of Interest: None \\ Permission from IRB: Yes
}

How to cite

Orji ML, Onyire NB, Onwe OE. Status Disclosure in HIV Infected Children in Abakaliki, Ebonyi State, Southeast, Nigeria. J Nepal Paediatr Soc 2017;37(3):244-249.

doi: http://dx.doi.org/10.3126/jnps.v37i3.18730

This work is licensed under a Creative Commons Attribution 3.0 License. 
address their mental health needs before beginning the disclosure process. Both the children and caregivers are likely to have more positive outcomes from disclosure if they have a strong support system to assist them ${ }^{2,3,4,5}$. The child's current developmental and cognitive stage should be considered as well as the existing family dynamics and communication ${ }^{2}$.

Majority of the parents of these infected children are positive with HIV, since MTCT is $>90 \%{ }^{6}$. There is the feeling of guilt concerning the child's illness and the fear that disclosure of child's HIV status to him/her may also disclose other secrets such as parental HIV status and sexual promiscuity ${ }^{7}$. As such many parents would not agree to communicate openly the child's status. Studies have shown that open communication with the child about his/her HIV diagnosis improved children's psychological adjustment ${ }^{8,9}$. The long interval before disclosure of the illness may play a part in the poor psychosocial adjustment that manifest in anger and resentment towards parents and caregivers ${ }^{9,10,11}$.

Status disclosure should be a graded process, but Vreemanet $\mathrm{al}^{12}$ in a review of 16 studies on disclosure of HIV status to children in resource limited setting observed that disclosure was mostly led by caregivers and as a one-time event. Status disclosure should be started as early as possible, preferably between the ages of 5-7 years and information given is gradual, starting with simple to complex issues ${ }^{13}$. Disclosure is achieved using tools and languages appropriate for the child's developmental capacity such as storytelling, cartoons, drama and use of flip charts ${ }^{13}$. Vreemanet $a^{12}$ reported level of status disclosure to be between 0 to $69.2 \%$. Mialky et al ${ }^{14}$ reported $43 \%$ disclosure rate with mean age of nine years, $23 \%$ of them have disclosed status to school authority, while Brown et a/15 in a study in Nigeria reported a lower level of status disclosure $(13.0 \%)$. Common barriers to status disclosure in the review by Vreeman et a/12 were fear that the child would disclose HIV status to others, fear of stigma and concerns of emotional and physical health of child.

There is paucity of data on disclosure of status of HIV infected children in Abakaliki, Southeast Nigeria. Hence the need for index study

The objectives of the study were to determine; the level of status disclosure among HIV infected children in Abakaliki, the pattern of disclosure among subjects and the relationship between disclosure of status and adherence to medication.

\section{Material and Methods}

Ebonyi State has a total population of $2,173,501$ people, majority of which are $\operatorname{lgbos}^{16}$. The study is a prospective hospital based study that was carried out in Federal Teaching Hospital Abakaliki (FETHA) Ebonyi State, from February to August 2017.

The Federal Teaching Hospital Abakaliki (FETHA) operates a provider-initiated HIV testing and counseling (PITC), in which every child that presents at the Children Out-patient Clinic is offered HIV antibody test irrespective of presenting complaint, except on objection by the caregiver, however objection (opt-out) of the caregiver to the screening test does not affect quality of treatment given to the child. Any child who tested positive to the test is referred to the Paediatrics Infection Disease Clinic for further evaluation and management.

Sample size was calculated using the prevalence rate reported by Brown et al ${ }^{15}$ (13.0\%) from which the sample size of 94 was obtained from the above prevalence rate. Subjects aged 5 years to 17 years, that had been regular to infectious disease clinic in the past one year prior to the study were recruited consecutively, until sample size was met. A structured questionnaire was used to obtain information.

All the subjects that participated in the study were on HAART. Immunological classification of subjects was done based on age related CD4+ T lymphocyte count and percentages. Based on this, subjects were classified as not significant, mild, advanced or severe. Subjects were advised to come for follow-up visit with their pill container. Assessment of adherence was done in the clinic by direct questioning and pill count.

Ethical approval was sought and obtained before commencement of this study. The study was explained to parents/guardian and only those who gave informed consent were included in the study.

The data obtained was entered into spread sheet using the Microsoft excel 2007 and the analysis was done using the Statistical Package for Social Science version 19.0. Quantitative variables were summarized using means and standard deviations. Frequency tables and charts were constructed as appropriate. The significance of associations between variables was tested using Chi-square and Fischer's exact tests for comparison of proportion. The level of statistical significance was achieved if $p<0.05$

\section{Results}

Thirty-one (33.0\%) subjects had received a form of information about their status from caregivers or health workers. The average age at disclosure was $12.48 \pm$ 2.46 , with an age range of 7 to 17 years. Subjects at 
mid (14-16 years) and late (>16 years) adolescent age groups had $100.0 \%$ disclosure when compared to $33.3 \%$ prevalence rate of disclosure seen in children at early adolescent (10-13 years) and $13.0 \%$ seen before the adolescent age as depicted in Table 1. There was a significant relationship between age and information given regarding HIV status as seen in Table 1

Among the subjects that have received information about their status, 22 (71.0\%) were given full information about HIV, majority of who are adolescents (95.5\%). Four $(12.9 \%)$ were told that they have an illness that require medication, $4(12.9 \%)$ were told that the illness that killed their parent (father) is what they are suffering from and one (3.2\%) was told storey about a disease that contaminates the blood in the body. Table 2 shows that More HIV disclosure was done in the hospital compared to home. Information about HIV status disclosure given at home was majorly partial (66.7\%). There was a significant relationship between information given in disclosure and venue of disclosure as shown in Table 2. Two adolescents were told that they had illness that required daily medications and one was told that he needed to take drugs so that what killed his parent would not kill him

The commonest reasons (47.6\%) why caregiver would not want to disclosure the HIV status to the subject was the belief that the subjects may not understand as shown in Table 3. Some other caregivers said that their children/wards were too young for such information, while others were afraid of disclosure to peers as depicted in Table 3 below

For majority of the subjects $(80.6 \%)$, disclosure was circumstantial. Only 6 (19.4\%) out of the 31 subjects knew their HIV status under no circumstance. Table 4 shows the circumstances that surrounded disclosure of HIV status in the subjects.

A significant number of subjects were adherent to their ART (85.1\%). Six (19.4\%) out of the 31 subjects that were aware of their HIV status were non-adherent to ART. Awareness of status did not have a significant relationship to adherence on ART as shown in Table 5 below.

Table 1: Relationship between socio-demographics and information given regarding HIV status

\begin{tabular}{lccc}
\hline \multirow{2}{*}{ Demographics } & \multicolumn{2}{c}{ Disclosure of HIV status } & p-value \\
\cline { 2 - 4 } Age (years) & Yes (\%) & No (\%) & \\
\hline$<10$ & $7(13.0)$ & $47(87.0)$ & - \\
\hline $10-13$ & $8(33.3)$ & $16(66.7)$ & - \\
\hline $14-16$ & $13(100.0)$ & $0(0.0)$ & - \\
\hline$>16$ & $3(100.0)$ & $0(0.0)$ & 0.344 \\
\hline Gender & & & - \\
\hline Male & $19(35.8)$ & $34(64.2)$ & - \\
\hline Female & $12(29.3)$ & $29(70.7)$ & 0.661 \\
\hline Social class & & & - \\
\hline Upper & $4(44.4)$ & $5(55.6)$ & $19(61.3)$ \\
\hline Middle & $12(38.7)$ & $39(72.2)$ & 0.890 \\
\hline Lower & $15(27.8)$ & & - \\
\hline Orphan status & & $23(63.8)$ & \\
\hline Yes & $13(36.1)$ & $40(69.0)$ & \\
\hline No & $18(31.00$ & & \\
\hline
\end{tabular}

Table 2: Pattern of information given, age and venue of information delivery

\begin{tabular}{lcccccc}
\hline \multirow{2}{*}{ Information given } & \multicolumn{2}{c}{ Venue } & p-value & \multicolumn{2}{c}{ Age group } & p-value \\
\cline { 2 - 7 } & Home (\%) & Hospital (\%) & & $\begin{array}{c}\text { Pre-adolescent } \\
(\%)\end{array}$ & $\begin{array}{c}\text { Adolescent } \\
(\%)\end{array}$ & - \\
\hline Illness requiring medication & $3(9.7)$ & $1(3.2)$ & - & $2(6.4)$ & $2(6.4)$ & - \\
\hline Story telling & $1(3.2)$ & $0(0.0)$ & - & $1(3.2)$ & $0(0.0)$ & - \\
\hline Has disease that killed parent & $4(12.9)$ & $0(0.0)$ & 0.001 & $3(9.7)$ & $1(3.2)$ & 0.105 \\
\hline Full information & $4(12.9)$ & $18(58.1)$ & - & $1(3.2)$ & $21(67.7)$ & - \\
\hline Total & $\mathbf{1 2 ( 3 8 . 7 )}$ & $\mathbf{1 9 ( 6 1 . 3 )}$ & - & $\mathbf{7 ( 2 2 . 6 )}$ & $\mathbf{2 4 ( 7 7 . 4 )}$ & - \\
\hline
\end{tabular}


Table 3: Reasons for non-disclosure of HIV status to subjects

\begin{tabular}{lcc}
\hline Reasons for non-disclosure of HIV status & Frequency & Percentage (\%) \\
\hline Patient is too young & 24 & 38.1 \\
\hline Patient may not understand & 30 & 47.6 \\
\hline Fear of disclosure to peers & 9 & 14.3 \\
\hline Total & $\mathbf{6 3}$ & $\mathbf{1 0 0 . 0}$ \\
\hline
\end{tabular}

Table 4: Circumstances surrounding disclosure of HIV status among subjects

\begin{tabular}{lcc}
\hline Circumstances & Frequency & Percentage (\%) \\
\hline Father's death & 4 & 12.9 \\
\hline Poor adherence to medication & 9 & 29.0 \\
\hline Frequent questioning & 1 & 3.2 \\
\hline III health of the child & 11 & 35.5 \\
\hline Not applicable & 6 & 19.4 \\
\hline Total & $\mathbf{3 1}$ & $\mathbf{1 0 0 . 0}$ \\
\hline
\end{tabular}

Table 5: Relationship between disclosure of HIV status and adherence to ART

\begin{tabular}{cccc}
\hline \multirow{2}{*}{ Awareness of HIV status } & \multicolumn{2}{c}{ Adherence to ART } & p-value \\
\cline { 2 - 4 } & Poor (\%) & Good (\%) & 0.832 \\
\hline Yes & $6(19.4)$ & $25(80.6)$ & - \\
\hline No & $8(12.7)$ & $55(87.3)$ & - \\
\hline Total & $14(14.9)$ & $80(85.1)$ & \\
\hline
\end{tabular}

\section{Discussion}

HIV infection defers from other chronic illnesses possibly due to stigma and discrimination attached to the HIV infections. When and how to disclose HIV status to children infected with HIV becomes an uphill task. A total of $31(33.0 \%)$ of HIV infected children studied had a form of information about their status. This is higher than $13.0 \%$ reported by Brown et $a^{/ 15}$ in a study in Ibadan, southwest, Nigeria but consistent with a later study carried out by Ubesie et $a{ }^{17}(29.0 \%)$. This suggests an increase in enlightenment and awareness of the need of disclosing HIV status to infected children. The mean age of HIV disclosure was found to be $12.48 \pm 2.46$ years in index study. This was rather late when compared to nine years reported by Mialky et al ${ }^{14}$ but similar to $11.52 \pm 2.25$ years reported by Ubesie et $a{ }^{17}$. Studies show that early disclose of HIV status like most chronic illnesses improves self esteem, reduces the risk to fantasies about illness and improves access to care and support. The delayed disclosure of HIV status observed in this study could be related to fear of the unknown. Many caregivers would prefer to hide the status of their children and/or wards until when they can no longer hide it due to ill-health or other circumstances

At the age of seven years, a child can ascent to a research meaning that he/she can understand and appreciate some level of information given. This is corroborated by Lansdown and Benjamin ${ }^{18}$ that reported that children by eight or nine years were able to fully understand the concept disease and death. However this study noted that majority of caregivers felt their children/ wards may not understand if told their status. This is gross assumption. The drawback to this assumption is that the subjects may likely get to know their HIV status inadvertently, creating room for mistrust and suspicion.

Status disclosure as seen in this study was mainly hospital based $(61.3 \%)$. This deferred from that observed by Vreemanet al ${ }^{12}$ who reported HIV status disclosure mostly by caregivers and done at home. The home environment is an ideal place for HIV disclosure because HIV disclosure is beyond just telling the child his/her HIV status. There is so much emotional and psychosocial interplay that if well harnessed would achieve the purpose of the disclosure. With the subject relaxed and unsuspecting in a home environment, the caregiver's self esteem and confidence is heightened and then the needed information is given as deemed right for the child age and cognition ${ }^{19,20}$. A total of $35.5 \%$ of subjects were told of their HIV status while on admission for ill-health in the health facility. All of whom were adolescents and were managed for HIVIAIDS related illness. Also all had history of ill-health that was managed by over the counter medications and traditional medicines. This underscores the need to improve health seeking behavior of caregivers in developing countries like Nigeria 
Vreemanet ${ }^{1 / 2}$ in a systematic review reported that the disclosure was a one-off event. This was similar to what was observed in this study. The subjects that were told at seven years that they had illness in their body that needed daily medication had no other information given even at age 11 and others that were told at the demise of their parents that the illness that their parents suffered and died from was what they have, did not receive any other information even at age 12.

It was also observed that $29.0 \%$ of subjects that received information about their HIV status were told because they were not adhering to drugs, so status disclosure became the means of re-enforcing adherence. Only $13.0 \%$ and $33.3 \%$ of pre-adolescents and mid adolescents respectively had information about why they are on drugs. The level of information given was graded and a total of $96.8 \%$ of subjects with full HIV disclosure were adolescents.

\section{References}

1. Wiener L, Mellins CA, Marhefka S, Battles HB Disclosure of an HIV diagnosis to children: History, Current Research, and Future Directions. J Dev BehavPediatr 2007;28(2):155-66. DOI:10.1097/01. DBP.0000267570.87564.cd

2. Lipson M. Disclosure of diagnosis to children with human immunodeficiency virus or acquired immunodeficiency syndrome. J Dev BehavPediatr. 1994;15(3): S61-65.

3. Havens JF, Mellins CA, Hunter J. Psychiatric Aspects of HIVIAIDS in childhood and adolescent. In: Rutter M, Taylor E, editors. Child and Adolescent Psychiatry: Modern Approaches. 4. Oxford, UK: Blackwell; 2002. pp.828-841.

4. Waugh S. Parental views on disclosure of diagnosis to their HIV infected children. AIDS Care. 2003;15:16976. DOI: $10.1080 / 0954012031000068317$

5. Flanagan-Klygis E, Ross LF, Lantos J, et al. Disclosing the diagnosis of HIV in pediatrics. J Clin Ethics. 2001 Summer;12(2):150-57.

6. National Guideline for Paediatric HIV and AIDS, Treatment and Care. Federal Ministry of Health of Nigeria. $2^{\text {nd }}$ edition. 2011;9-43

7. Wolters PL, Brouwers P. Neurobehavioral function and assessment of children and adolescent with HIV-1 infection. In: Zeichner SL, Read JS, editors. Textbook of Pediatric Care. Cambridge: Cambridge University Press; 2005

8. Blasini I, Chantry C, Cruz C, et al. Disclosure model for pediatric patients living with HIV in Puerto Rico. J Dev Behav Pediatr 2004;25(3):181-89.
Adherence to medication is a shared responsibility between health care provider and a subject who has understood the need for drugs and is willing to take the right dose of drug and at the right time following an agreed plan. This study noted that $81.5 \%$ of subjects were adherent to drugs but there was no significant relationship between adherence to drugs and HIV status disclosure. However a look at the circumstances surrounding disclosure and the information given at disclosure, raises questions as to whether the subjects where compelled to take their drugs or they were actually adherent to their antiretroviral.

\section{Conclusion}

The prevalence rate of HIV status disclosure in this study was low, done rather late and mostly in a hospital setting by healthcare providers. Parents and caregivers should be empowered with knowledge and skill to disclose HIV status to their wards

9. Instone SL. Perception of children with HIV infection when not told for so long: Implications for diagnosis disclosure. J Pediatr Health Care 2000;14:235-43.

10. Letteney $\mathrm{S}$, HeftLaPorte $\mathrm{H}$. Deconstructing stigma: Perception of HIV seropositive mothers and their disclosure to children. Social Work in Health Care 2004;38(3):429-37.

11. Perrin EC, Gerrity PS. There's a demon in your belly: children's understanding of illness. Pediatrics 1981;67:841-49.

12. Vreeman RC, Gramelspacher AM, Gisore PO, Scanlon ML, Nyandiko WM. Disclosure of HIV status to children in resource limited settings: a systemic review. $J$ Int AIDS Soc 2013; 16:18466

13. Lester $P$, Chesney $M$, Cooke $M$, et al. Diagnostic disclosure to HIV-infected children: How parents decide when and what to tell. Clin Child Psychol Psychiatr 2002;7(1). Available at journal.sagapub.com/ doi/abs/10.1177/1359104502007001007. Accessed on the $14 / 03 / 17$

14. Mialky E, Vagnoni J, Rutstein R. School-age children with perinatally acquired HIV infection: Medical and psychosocial issues in a Philadelphia cohort. AIDS Pt Care STDs 2001;15: 575-79.

15. Brown BJ, Oladokun RE, Osinusi K, Ochigbo S, et al. Disclosure of HIV status to infected children in a Nigerian HIV care programme. AIDS care 2011;23(9):1053-8. DOI: $10.1080 / 09540121.2011 .554523$

16. Federal Republic of Nigeria. 2006 population and housing census of Nigeria. Federal Republic of Nigeria official gazette. Lagos 2007; 94.

17. Ubesie AC. Iloh KK, Emodi IJ, Ibeziako IN, ObumnemeAnyim ON, Iloh ON. Sahara-J. HIV status disclosure 
rate and reasons for non-disclosure among infected children and adolescents in Enugu, southeast Nigeria. J Soc Aspects HIVIAIDS. 2016;13(1):136-40. DOI: 10.1080/17290376.2016,1226942

18. Lansdown R, Benjamin G. The development of the concept of death in children aged 5-9 years. Child Care, Health Development 1985;11(1):13-20.
19. Guideline on HIV Disclosure Counseling for children up to 12 years of age. World Health Organization 2011, 20 Avenue Appia, 1211 Geneva 27, Switzerland

20. American Academy of Pediatrics Committee on Pediatrics AIDS. Disclosure of illness to children and adolescents with HIV infection. Pediatrics 1999;103(1):109-39. 